\title{
PERAN PEKERJA SOSIAL DALAM PEMBERDAYAAN DAN PERLINDUNGAN SOSIAL KLIEN DI LEMBAGA KONSULTASI KESEJAHTERAAN KELUARGA "TERATAI" YOGYAKARTA
}

\section{THE ROLE OF SOCIAL WORKERS IN THE EMPOWERMENT AND SOCIAL PROTECTION OF CLIENT IN LK3 (FAMILY WELFARE CONSULTANCY) "TERATAI" YOGYAKARTA}

\author{
Oleh: \\ Muh.Adam Kurniawan, Universitas Negeri Yogyakarta \\ muhadamovich@gmail.com
}

\begin{abstract}
Abstrak
Penelitian ini bertujuan untuk mendeskripsikan: (1) Pelaksanaan pelayanan terhadap klien yang ada di LK3 Teratai, (2) Peran pekerja sosial dalam pemberdayaan dan perlindungan sosial klien di LK3 Teratai, dan (3) Faktor pendukung dan penghambat yang dihadapi pekerja sosial dalam menjalankan perannya. Penelitian ini dengan pendekatan kualitatif dan dengan metode deskriptif. Subjek penelitian ini adalah Kepala, Pekerja Sosial, dan Klien LK3 Teratai. Pengumpulan data dilakukan dengan menggunakan teknik observasi, wawancara, dan dokumentasi. Teknik yang digunakan dalam analisis data adalah reduksi data, penyajian data, dan penarikan kesimpulan. Teknik yang digunakan untuk menjelaskan keabsahan data adalah dengan menggunakan triangulasi sumber dan triangulasi teknik. Hasil penelitian menunjukkan bahwa: (1) Pelaksanaan pelayanan terhadap klien melalui dua tahap (2) Peran pekerja sosial dalam pemberdayaan, meliputi sebagai pendamping klien sebelum sampai setelah kegiatan pemberdayaan, sebagai fasilitator dari dinas sosial kepada klien, dan sebagai konsultan klien dalam membantu menentukan bantuan. Sedangkan peran pekerja sosial dalam perlindungan sosial, meliputi sebagai pendamping, sebagai pelindung klien dari ancaman yang bisa saja menimpa klien. (3) Faktor pendukung pekerja sosial dalam menjalankan perannya yaitu Komitmen/panggilan hati, dukungan keluarga, dan dukungan mitra lembaga dan dinas terkait. Faktor penghambat yaitu kurang keterbukaan klien dan dana yang terbatas.
\end{abstract}

Kata kunci : pekerja sosial, pemberdayaan, perlindungan sosial, LK3

\begin{abstract}
This study aims to describe: (1) Implementation of services to clients in LK3 "Teratai", (2) The role of social workers in empowerment and protection social of clients in LK3 "Teratai", and (3) Supporting and inhibiting factors faced by social workers in carrying out its role. This research is a descriptive research with qualitative approach. The subjects of this research are Chairman, Social Worker, and Client of LK3 "Teratai". The data were collected using observation, interview and documentation techniques. Techniques used in data analysis are data reduction, data presentation, and conclusion. The technique used to explain the validity of data is by using triangulation of source and triangulation technique. The results of the research indicate that: (1) Implementation of service to client through two stages (2) The role of social workers in empowerment, encompassing as client assistants prior to after empowerment activities, as facilitators of social services to clients, and as client consultants in helping to determine aid. While the role of social workers in social protection, including as a companion, as a protector of the client from threats that could befall the client. (3) Social worker supporting factor in carrying out its role is Commitment/desire, family support, and support partner of institution and related offices. Inhibiting factors are lack of client openness and limited funds.
\end{abstract}

Key words : social worker, empowerment, social protection, LK3

\section{PENDAHULUAN}

Indonesia merupakan negara

berkembang yang sedang mengalami proses

pembangunan pada beberapa. Pembangunan yang dilakukan pemerintah tidak hanya tertuju pada pembangunan pada ekonomi dan keamanan. Pembangunan pada sosial budaya tidak kalah penting untuk dilakukan pembangunan. Pembangunan pada sosial budaya ini perlu adanya gotong royong antara pemerintah dengan masyarakat dalam 


\section{Diklus: Jurnal Pendidikan Luar Sekolah, 2(1), Maret 2018 - 46 Muh. Adam Kurniawan}

melaksanakannya. Dalam proses pembangunan menurut Ryaas Rasyid dalam Muhadam Labolo (2010: 32), ada 4 bagian peran pemerintah, yaitu pelayanan (public service), pembangunan (development), pemberdayaan (empowering), dan pengaturan (regulation).

Pemberdayaan menunjuk pada kemampuan orang khususnya kelompok rentan dan lemah dan tidak memiliki akses sehingga mereka memiliki kekuatan atau kemampuan dalam berbagai dimensi kehidupannya. Proses pemberdayaan yang menekankan pada proses memberikan kemampuan kepada masyarakat agar menjadi berdaya, mendorong atau memotivasi individu agar mempunyai kemampuan atau keberdayaan untuk menentukan pilihan hidupnya. Lebih lanjut bahwa pemberdayaan harus ditujukan pada kelompok atau lapisan masyarakat yang tertinggal. Pemberian kegiatan pemberdayaan khususnya kepada kelompok masyarakat lemah/tertinggal secara tidak langsung akan memberikan kebebasan kepada masyarakat yang lemah untuk ikut berpartisipasi dalam proses pembangunan kesejahteraan sosial, karena partisipasi masyarakat dalam pemberdayaan memiliki peranan penting kegiatan tersebut dapat berjalan dengan lancar. Dengan kelancaran kegiatan pemberdayaan kepada kelompok masyarakat lemah diharapkan akan berdampak pada kesejahteraan sosial pada masyarakat lemah tersebut. Namun pada kenyataannya yang banyak terjadi, kegiatan pemberdayaan yang ada di masyarakat masih belum menjangkau semua lapisan masyarakat atau bahkan salah sasaran.

Kesejahteraan Sosial adalah kondisi dimana terpenuhinya kebutuhan material, spiritual, dan sosial warga negara dapat hidup layak dan mampu mengembangkan diri, sehingga dapat melaksanakan fungsi sosialnya (UU No. 11 Tahun 2009 Pasal 1). Dalam suatu masyarakat tentu saja tidak bisa terlepas dari adanya keluarga. Keluarga adalah unit terkecil dalam masyarakat. Keberadaaan sebuah keluarga akan mencerminkan kehidupan yang ada dimasyarakat. Karena keluarga juga sebagai suatu sistem sosial, maka harus memberikan kebutuhan masing-masing anggota, seperti yang dikemukakan oleh Kathryn Geldard dan David Geldard (2011) ada empat kebutuhan yang harus dipenuhi yaitu keamanan dan keselamatan, kesejahteraan ekonomi dan materi, kesejahteraan psikologi, fisik, dan emosional, dan kebutuhan-kebutuhan spiritual.

\section{Lembaga Konsultasi Kesejahteraan} Keluarga dibentuk sebagai amanah UU No. 11 Tahun 2009 tentang Kesejahteraan Sosial. Lembaga Konsultasi Kesejahteraan Keluarga (LK3) "Teratai" merupakan lembaga sosial yang berada dibawah naungan Dinas Sosial DIY. LK3 "Teratai" memberikan layanan berupa jasa konseling, konsultasi, rujukan, informasi, perlindungan dan pemberdayaan, yang juga memiliki struktur organisasi baik tenaga fungsional maupun pekerja sosial. LK3 "Teratai" sendiri merupakan salah satu lembaga yang berbasis ada masyarakat dalam 


\section{Diklus: Jurnal Pendidikan Luar Sekolah, 2(1), Maret 2018 - 47 \\ Muh. Adam Kurniawan}

pelaksanaannya. Keberadaan LK3 "Teratai" diharapkan bisa membantu memecahkan masalah yang dihadapi keluarga yang ada di Yogyakarta. Permasalahan yang sering ditangani LK3 Teratai seperti kasus kekerasan dalam rumah tangga (KDRT), keluarga penyandang gangguan jiwa (Psikotik) disharmonis keluarga, keluarga yang mengalami masalah psikososial dan sebagainya. Keberdaan lembaga sudah banyak dimanfaatkan oleh masyarakat untuk membantu menangani permasalahan mereka. Tetapi dalam pelaksanaanya tidak semua keluarga (klien) yang datang membuka permasalahannya secara gamblang kepada pihak LK3, banyak juga dari pihak keluarga (klien) kurang terbuka dalam menyampaikan informasi, keluarga juga sering berhenti ditengah jalan atau tidak tuntas dalam menangani permasalahan terkait permasalahan yang menimpa keluarganya tentu saja ini menjadi salah satu penghambat dalam penanganan.

Dan tentu saja dalam menangani permasalahan tersebut keberadaan pekerja sosial saat ini sangat dibutuhkan untuk membantu klien dalam memecahkan permasalahannya. Terlebih dengan latar belakang para pekerja sosial yang berbedabeda akan membantu menggali dan menangani permasalahan dari setiap klien tersebut. Selain itu juga keberadaan pekerja sosial memiliki peran yang sangat strategis dan penting, karena mereka langsung berhadapan dengan klien sehinggan mereka dapat mengetahui apa permasalahan dari klien. Untuk itu penulis berupaya melakukan penelitian dengan menggali informasi tentang peran pekerja sosial di LK3 “Teratai” pada saat memberikan layanan kepada keluarga yang bermasalah terutama pada pemberdayaan dan perlindungan serta faktor pendukung dan penghambat yang dihadapi para pekerja sosial dalam menjalankan perannya.

Berdasarkan uraian diatas, maka penulis mencoba melakukan penelitian yang berjudul "Peran Pekerja Sosial dalam Pemberdayaan dan Perlindungan Sosial Klien Di Lembaga Konsultasi Kesejahteraan Keluarga (LK3) “Teratai” Yogyakarta”.

\section{METODE PENELITIAN}

Metode yang digunakan dalam penelitian ini adalah pendekatan kualitatif. Sugiyono (2013:9) pendekatan kualitatif adalah metode penelitian yang berlandaskan pada filsafat postpositivisme, digunakan untuk meneliti pada kondisi objek yang alamiah, (sebagai lawannya adalah eksperimen) dimana peneliti adalah sebagai instrumen kunci, teknik pengumpulan data dilakukan secara trianggulasi (gabungan), analisis data bersifat induktif/kualitatif, dan hasil penelitian kualitatif lebih menekankan makna dari pada generalisasi.

\section{Waktu Dan Tempat Penelitian}

Waktu penelitian ini dilakukan selama kurang lebih 3 bulan, yaitu pada tanggal 12 April 2017 - 30 Juni 2017. Tempat penelitian ini 


\section{Diklus: Jurnal Pendidikan Luar Sekolah, 2(1), Maret 2018 - 48 \\ Muh. Adam Kurniawan}

dilakukan oleh peneliti di dua tempat, yaitu Kantor LK3 Teratai dan Kotagede. Kantor LK3 Teratai yang beralamatkan di Jl. Lempuyangan No. 1 Yogyakarta. Sedangkan di Kotegede dilaksanakan merupakan alamat tempat tinggal klien LK3 Teratai yang pernah mengikuti kegiatan Pemberdayaan.

\section{Subjek Penelitian}

Subjek dalam penelitian ini adalah Kepala LK3 Teratai, Pekerja Sosial LK3 Teratai, dan Klien LK3 Teratai. Informasi yang akan digali dari pekerja sosial adalah perannya dalam kegiatan pemberdayaan dan juga perlindungan sosial, serta faktor pendukung dan penghambat dalam menjalankan perannya. Subjek yang diambil oleh peneliti untuk digunakan sebagai sumber data penelitian berjumlah 7 orang yaitu 1 orang sebagai Kepala lembaga LK3 Teratai, 4 orang sebagai Pekerja Sosial di LK3 Teratai, dan 2 orang klien LK3 Teratai.

\section{Prosedur}

Jenis penelitian ini adalah deskriptif kualitatif. Semua data diperoleh melalui teknik wawancara, observasi partisipatif dan dokumentasi.

\section{Data, Instrument, Dan Teknik Pengumpulan Data}

Sumber data yang diperoleh adalah data primer yang diperoleh melalui wawancara dan observasi di LK3 Teratai. Selain itu data sekunder diperoleh melalui buku, internet maupun laporan pelaksanaan dari LK3 Teratai. Instrumen penelitian adalah peneliti sendiri. Peneliti sebagai human instrument berfungsi menetapkan focus penelitian, memilih subyek penelitian sebagai sumber data, menilai kualitas data, dan membuat kesimpulan dan beberapa temuan.

Untuk mengecek keabsahan data, peneliti menggunakan teknik pemeriksaan trianggulasi sumber dan teknik. Trianggulasi data dilakukan dengan cara membandingkan data hasil penelitian ini mengecek informasi data hasil yang diperoleh dari : wawancara dengan hasil observasi dan dokumentasi yang didapatkan selama melakukan penelitian. Teknik analisis data meliputi data reduksi, data penyajian data dan penarikan kesimpulan.

\section{HASIL PENELITIAN DAN PEMBAHASAN}

\section{Pelaksanaan Kegiatan di Lembaga}

Konsultasi Kesejahteraan Keluarga (LK3)

\section{Teratai}

\section{Proses Perekrutan Klien}

Berdasarkan hasil wawancara, observasi, dan dokumentsi yang dilakukan peneliti didapat bahwa dalam melakukan perekrutan klien, pihak LK3 dengan memberikan alamat lokasi LK3 Teratai kepada masyarakat pada saat mengadakan penyuluhan. Masyarakat datang dengan sendirinya. Selain itu sistem jemput bola juga dilakukan apabila dirasa perlu atau ada masalah sosial yang 


\section{Diklus: Jurnal Pendidikan Luar Sekolah, 2(1), Maret 2018 - 49 \\ Muh. Adam Kurniawan}

dalam penenganannya klien tidak bisa datang ke kantor LK3 Teratai.

Jika kita melihat pada jurnal rekrutmen SDM pada sumber-sumber rekrutmen, hal tersebut juga sesuai dengan salah satu poin dalam sumber-sumber rekrutmen yang menyatakan bahwa adanya applications at the gate, para pencari datang sendiri ke organisasi/lembaga, tanpa mengetahui apakah dilembaga bisa atau tidak.

Sehingga tidak selalau dalam proses perekturan dari pihak organisasi/lembaga yang mencari tetapi juga bisa dari pihak individulah yang mencari sendiri keberadaan dan cara mendapatkannya.

\section{Proses Penanganan Klien}

Berdasarkan hasil wawancara, observasi, dan dokumentsi yang dilakukan peneliti didapat bahwa bahwa dalam proses penanganan klien yang dilakukan oleh LK3 meliputi pencatatan-identifikasi identitas klien, pemberian konseling, home visit, pemberdayaan serta rujukan apabila tidak dapat diselesaikan oleh LK3. Sehingga akan diperoleh keluarga yang kembali mandiri dan sejahtera serta dapat memperkuat ketahanan keluarga tersebut. Proses penanganan yang dilakukan di LK3 Teratai dilakukan secara sistematis namun juga disesuaikan dengan kebutuhan dan permasalahan klien. Proses penanganan/pelayanan dilakukan oleh tim ahli dibidangnya masing-masing. Proses penanganan awal dilakukan setelah klien mendaftar di bagian administrasi, setelah itu klien diberikan konseling bersama ahlinya. Pemilihan tim ahli diberikan sesuai dengan permsalahan yang di hadapi klien dan yang berkompeten dalam menanganinya. Selain dengan pemberian konseling, juga dilakukan home visit untuk mengetahui dan mencari kebenaran dari informasi klien.

Apabila bisa diselesaikan di LK3 Teratai berarti permsalahan klien sudah tuntas, tetapi apabila tidak bisa diselesaikan di LK3 Teratai, akan diberikan rujukan ke lembaga lain/lembaga mitra. Untuk permasalahan yang tidak bisa di selesaikan oleh pihak LK3 Teratai, pihak LK3 Teratai bekerja sama dengan lembaga-lembaga lain yang berkompeten untuk menangani permasalahan keluarga. Jadi dengan proses rujukan, klien diberikan pendampingan untuk ke lembaga mitra supaya permasalahannya terselesaikan

\section{Peran Pekerja Sosial Dalam Pemberdayaan} dan Perlindungan Sosial Di LK3 Teratai Yogyakarta

Peran Pekerja Sosial dalam Pemberdayaan Peran pekerja sosial dalam pemberdayaan memiliki peran yang bermacam-macam, yaitu sebagai

Memberikan pendamping kepada peserta/klien, Pendampingan diawali dari melakukan asesmen, yakni mengungkap permasalahan untuk mendapatkan klien yang sesuai dengan kegiatan pemberdayaan.

Selanjutnya melakukan home visit, melihat langsung keadaan dirumah/keluarga dan lingkungan klien yang akan mengikuti pemberdayaan. Selanjutnya melakukan pendampingan usaha, setelah mengikuti pemberdayaan (pelatihan dan menerima 


\section{Diklus: Jurnal Pendidikan Luar Sekolah, 2(1), Maret 2018 - 50 \\ Muh. Adam Kurniawan}

bantuan sosial). (2) Sebagai fasilitator yang memfasilitasi kegiatan, Pihak LK3 Teratai juga berarti memfasilitasi klien dengan meminta kliennya untuk mengikuti program yang diberikan oleh Dinas Sosial. Biasanya juga tempat kegiatan dilakukan di LK3 Teratai. Sebagai fasilitator, pekerja sosial juga memberikan pendampingan kepada klien dengan mengikuti kegiatan dan juga menjadi narasumber bagi klien.dan juga (3) Sebagai konsultan bagi peserta/klien yang masih bingung dalam mengambil keputusan.

Dalam pemberdayaan dan perlindungan LK3 Teratai juga digunakan oleh para klien untuk berkonsultasi dalam menentukan yang terbaik untuk klien.

\section{Peran Pekerja Sosial dalam Perlindungan} Sosial

Peran Pekerja Sosial dalam Perlindungan Sosial khususnya kepada klien tujuannya adalah melindungi klien dari masalahnya kembali, supaya mereka dapat hidup sejahtera. Selian itu juga merahasiakan data-data klien. Selain memberikan perlindungan kepada klien secara nyata, perlindungan juga diberikan dengan merahasiakan data-data terkait klien. Hal itu juga sesuai dengan pendapat Suharto (2011), yang menyatakan bahwa perlindungan biasanya dilakukan oleh bidang aparat, tetapi profesi pekerja sosial dapat mengambil peran seperti melindungi klien. Klien merasa nyaman untuk mengutarakan permasalahannya, bebas dalam pikiran, dan merasa bahwa masalahnya dirahasiakan oleh pekerja sosial.

\section{Faktor Pendukung Pekerja Sosial}

Faktor pendukung pekerja sosial di LK3 Teratai dipengarui oleh beberapa faktor, selain dari dalam diri sendiri, faktor pendukung dari luar juga sangat berpengaruh. (a) komitmen/ panggilan hati, Komitmen merupakan suatu tanggung jawab atas suatu peranan dalam melakukan atau menyelesaikan tugas tertentu. Pekerja sosial yang ada di LK3 Teratai merupakan pensiunan dari berbagai Dinas dan Lembaga Sosial yang masih mau untuk mengabdikan diri membantu LK3 Teratai. Secara umur pekerja sosial di LK3 Teratai sebaiknya bersantai menikmati masa tua/pensiun mereka dirumah dengan tenang. Karena mereka bekerja di LK3 teratai tidak digaji seperpun dari LK3 Teratai ini. Panggilan dari hati ini yang membukakan niat mereka berkomitmen untuk membantu yang mengalami permasalahan. (b) dukungan keluarga, Dukungan keluarga menjadi motivasi tersendiri bagi pekerja sosial di LK3 Teratai. Keluarga menjadi faktor yang mendukung pekerja sosial untuk masih menjalani kegiatan sosial mereka. Karena apabila keluarga tidak memberikan dukungan, pekerja sosial juga akan tidak nyaman dalam menjalani peran mereka membantu orang lain, selalu ada ganjalan. dan (c) dukungan mitra lembaga, Keberdaaan mitra lembaga dan dinas juga memberian dukungan tersendiri bagi pekerja sosial di LK3 Teratai. Dari dinas terkait yang selalu bekerjasama menyelenggarakan program-program terutama pemberdayaan yang dari pihak LK3 Teratai tidak memiliki 


\section{Diklus: Jurnal Pendidikan Luar Sekolah, 2(1), Maret 2018 - 51 \\ Muh. Adam Kurniawan}

dana untuk menyelenggaraannya. Selain itu juga selalu memberikan dana operasional tahunan untuk membantu pekerja sosial dan LK3 Teratai menangani permasalahan. Selain dari dinas-dinas terkait, peran dari lembaga mitra juga sangat membantu LK3 Teratai. Dalam memberikan penanganan kepada klien apabila pihak LK3 Teratai tidak bisa menyelesaikan, dari pihak mitra lembaga bisa digunakan untuk melakukan rujukan dalam menangani permasalahan klien..

\section{Faktor Penghambat Pekerja Sosial}

Adapun faktor penghambat dalam peran pekerja sosial di LK3 Teratai dalam menjalankan perannya adalah (a) Klien yang susah diungkap informasinya, Latar belakang dan karakter dari klien ynag datang ke LK3 Teratai tidak jarang menyulitkan pekerja sosial dalam mengungkap informasi dari klien. Kurangnya keterbukaan dari pihak klien menjadi penghambat sekaligus tantangan sendiri bagi pekerja sosial. dan juga (b) dana yang terbatas, LK3 Teratai memang tidak memiliki dana yang bisa digunakan, termasuk oleh pekerja sosial dalam memberikan program kegiatan. Dana yang dimiliki oleh LK3 Teratai setiap tahun hanya dana operasional lembaga. Kalau dana itu digunakan untuk melakukan kegiatan tentu saja tidak akan cukup, terlebih dengan pemberian bantuan sosial kepada peserta. Ini juga menjadi salah satu faktor penghambat pekerja sosial dalam menjalankan perannya

\section{Simpulan}

Berdasarkan hasil penelitian dan pembahasan, maka dapat ditarik kesimpulan sebagai berikut:

\section{Pelaksanaan Kegiatan Lembaga Konsultasi} Kesejahteraan Keluarga di LK3 Teratai

Proses perekrutan klien yang dilakukan oleh LK3 Teratai dilakukan dalam 2 cara yaitu Klien datang sendiri ke LK3 Teratai dan jemput bola, jemput bola apabila ada permintaan dari masyarakat. Dan Proses penanganan klien yang dilakukan oleh LK3 Teratai, dilaksanakan melalui beberapa prosedur. Penanganan yang dilakukan oleh LK3 Teratai antara lain: Konseling, Home Visit, Pemberdayaan, serta Rujukan apabila tidak bisa diselesaikan oleh LK3 Teratai.

Peran Pekerja Sosial Yang Ada Di LK3 Teratai dalam Pemberdayaan dan Perlindungan Sosial:

a. Peran Pekerja Sosial dalam Pemberdayaan yaitu Pekerja sosial sebagai Pendamping, fasilitator dan konsultan

b. Peran Pekerja Sosial dalam Perlindungan Sosial yaitu pekerja sosial sebagai pendamping dan juga pelindung.

Faktor pendukung meliputi komitmen diri sendiri, dukungan keluarga serta dukungan mitra lembaga dan dinas terkait. Sedangkan faktor penghambatnya meliputi kurangnya keterbukaan dari klien serta dana yang terbatas. 


\section{Saran}

Setelah melakukan penelitian terhadap Peran Pekerja sosial dalam Pemberdayaan dan perlindungan Klien di LK3 Teratai maka dijadikan beberapa saran sebagai berikut:

Pekerja Sosial untuk berkerja sama dengan pekerja sosial atau lembaga lain dibidangnya, supaya kurang keterbukaan klien dapat diatasi dengan baik sesuai kemampuan pihak yang bisa menanganinya.

Supaya LK3 Teratai di setiap tahunnya mengajukan proposal pengajuan dana (seperti LK3 lain) ke Dinas Sosial atau yang terkait supaya bisa menambah dana operasional. Walaupun sudah ada dana operasional tiap tahun yang saat ini, namun itu dirasa masih kurang untuk melakukan kegiatan bagi para klien LK3 Teratai.

\section{DAFTAR PUSTAKA}

Kathryn Geldard dan David Geldard. 2011.

Konseling Keluarga. Yogyakarta:

Pustaka Pelajar

Labolo, Muhadam. 2010. Memahami Ilmu Pemerintahan Suatu Kajian, Teori, Konsep, dan Pengembangannya. Jakarta: Rajawali Pers

Sugiyono. 2013. Metode Penelitian

Pendidikan; Pendekatan Kuantitatif, Kualitatif, dan R\&D. Bandung:

Alfabeta

Undang-Undang No. 11 Tahun 2009 tentang Kesejahteraan Sosial 